\title{
SPREAD OVERREACTION IN INTERNATIONAL BOND MARKETS
}

by

Gregory D. Sutton

June 1998

BANK FOR INTERNATIONAL SETTLEMENTS

Monetary and Economic Department

BASLE 
BIS Working Papers are written by members of the Monetary and Economic Department of the Bank for International Settlements, and from time to time by other economists, and are published by the Bank. The papers are on subjects of topical interest and are technical in character. The views expressed in them are those of their authors and not necessarily the views of the BIS.

(C) Bank for International Settlements 1998

CH-4002 Basle, Switzerland

Also available on the BIS World Wide Web site (http://www.bis.org).

All rights reserved. Brief excerpts may be reproduced or translated provided the source is stated.

ISSN 1020-0959 


\title{
SPREAD OVERREACTION IN INTERNATIONAL BOND MARKETS *
}

\author{
by
}

Gregory D. Sutton

June 1998

\begin{abstract}
This paper applies the Campbell-Shiller (1987) methodology to a study of the joint behaviour of a three-month and a five-year government yield in the United States, Canada, the United Kingdom, Germany and Japan. The period studied is for most countries the mid-1970s to the third quarter of 1997. The empirical results allow the rejection of the expectations theory of the term structure at high levels of statistical significance in every country except Japan. Furthermore, in every country where the expectations theory fails, the failure of the theory is consistent with the spread overreaction hypothesis of Froot (1989) and Campbell and Shiller (1991). This implies that the departures of long rates from levels predicted by the expectations theory in many major markets cannot be attributed to white noise error terms.
\end{abstract}

I would like to thank Palle Andersen and Joseph Bisignano for their comments on earlier versions of this paper. I am also indebted to Stephan Arthur for his statistical and graphical assistance. 



\section{Contents}

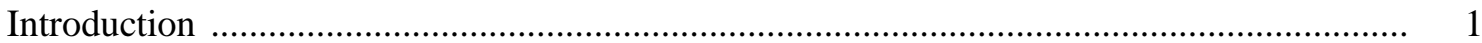

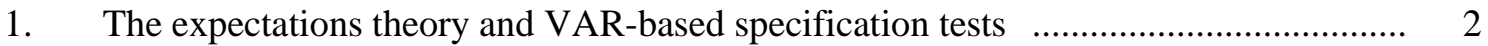

1.1 VAR-based specification tests of the expectations theory ................................. 3

2. Spread overreaction and comovements of term premia between countries $\quad \ldots \ldots \ldots \ldots \ldots \ldots . . . . .6$

$2.1 \quad$ Spread overreaction hypothesis ………………........................................... $\quad 7$

2.2 Comovements of term premia between countries ……........................................ 8

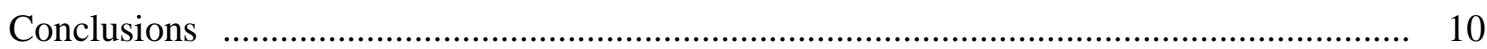

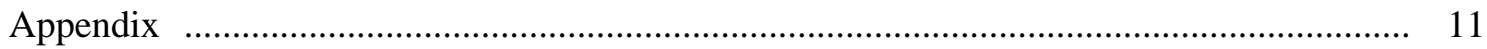

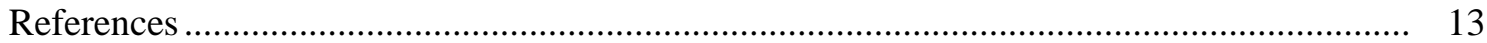





\section{Introduction}

In their study of the behaviour of US interest rates, Campbell and Shiller (1991) conclude that the failure of the expectations theory of the term structure across the maturity spectrum is consistent with the spread overreaction hypothesis of Froot (1989). ${ }^{1}$ According to the spread overreaction hypothesis, longer-term interest rates overreact to shifts in the (rational) forecast of the path of shorter-term interest rates. Consequently, long/short interest rate spreads tend to be more volatile than the expectations theory would predict.

In previous work (Sutton (1997)), I present evidence which suggests that there is an international component to departures of long-term interest rates from levels predicted by the expectations theory of the term structure. In that study, I examine the behaviour of a three-month and a ten-year government yield for five of the major industrialised countries (the United States, Canada, the United Kingdom, Germany and Japan) from either the late 1960s or early 1970s to the early 1980s. The regression tests reported in that paper support the view that there is a common component to predictable excess returns on long-term bonds across the markets studied. This implies that term premia at the long end of the term structure are both time-varying and positively correlated across countries. I call this phenomenon excess comovement of bond yields between countries, and it suggests that there is a common explanation for the international failure of the expectations theory at the long end of the term structure. ${ }^{2}$

Given the findings of Campbell and Shiller (1991), a candidate explanation for the international failure of the expectations theory at the long end of the term structure is the spread overreaction hypothesis. The purpose of this paper is to confront the spread overreaction hypothesis with international interest rate data. To this end, the paper applies the vector autoregressive methodology of Campbell and Shiller (1987) to a study of the joint behaviour of a three-month and a five-year government yield in each of the same five countries -- the United States, Canada, the United Kingdom, Germany and Japan.

The paper is organised as follows. Section 1 briefly discusses the Campbell-Shiller (1987) approach to testing the expectations theory of the term structure and reports the results of an application of the methodology to a study of the behaviour of long/short interest rate spreads in each country. On the basis of standard specification tests, the expectations theory of the term structure is rejected at high levels of statistical significance in every country except Japan. Furthermore, the

1 There is a vast empirical literature which tests the implications of the expectations theory of the term structure with US interest rate data. This includes the studies by Shiller (1979), Shiller et al. (1983), Campbell and Shiller (1984), Fama (1984) and Fama and Bliss (1987).

2 Hardouvelis (1994) and Sutton (1997) document the statistical rejection of the expectations theory at the long end of the term structure in the majority of G-7 countries. 
results of the empirical analysis suggest that, in the majority of markets studied, bond yields have in the past displayed relatively large deviations from levels predicted by the expectations theory. Section 2 examines, in greater detail, the failure of the expectations theory as a model of the behaviour of bond yields internationally. It is shown that, in every country where the expectations theory fails, the failure of the theory is consistent with the spread overreaction hypothesis of Froot (1989) and Campbell and Shiller (1991). This section also addresses some of the implications of spread overreaction for the comovements of term premia between countries. The final section presents conclusions.

\section{The expectations theory and VAR-based specification tests}

According to the expectations theory of the term structure, a long-term interest rate equals the sum of a constant term premium and a weighted average of current and expected future short rates. More formally, let $R_{i t}^{e}$ denote the $n$-period bond yield in country $i$ at time $t$ implied by the expectations theory and let $r_{i t}$ represent the one-period rate of interest. Following Shiller et al. (1983), the expectations theory of the term structure is the statement that these two rates satisfy the relation

$$
R_{i t}^{e}=\theta_{i}+\sum_{j=0}^{n-1} w_{i j} E_{t} r_{i, t+j}
$$

where $\theta_{i}$ is a constant term premium, $E_{t}$ is the expectations operator given time $t$ information and $\left\{w_{i j}\right\}$ are weights which depend upon the duration of the $n$-period bond. The weights satisfy

$$
w_{i j}=g_{i}^{j}\left(1-g_{i}\right) /\left(1-g_{i}^{n}\right)
$$

where $g_{i} \equiv 1 /\left(1+\bar{R}_{i}\right)$ and $\bar{R}_{i}$ is the average $n$-period bond yield over the sample period. ${ }^{3}$

The theoretical long/short interest rate spread is $S_{i t}^{e} \equiv R_{i t}^{e}-r_{i t}$. From equation (1.1) it follows that

$$
S_{i t}^{e}=\theta_{i}+\sum_{j=1}^{n-1} \omega_{i j} E_{t} \Delta r_{i, t+j}
$$

where $\omega_{i j}=w_{i j}+w_{i, j+1}+\ldots+w_{i, n-1}$ and $\Delta r_{i, t+j}=r_{i, t+j}-r_{i, t+j-1}$. Thus, equation (1.1) implies that the theoretical long/short spread is equal to a constant plus a linear combination of expected changes of the one-period (short) rate. In contrast, the actual spread, $S_{i t} \equiv R_{i t}-r_{i t}$, is the difference between the actual long rate in country $i$ at time $t, R_{i t}$, and the one-period rate. Of course, the discrepancy between the actual and theoretical spreads

3 In the empirical work which follows, the sample period is 1975 Q2-1997 Q3. An implication of relation (1.2) is that the weights in equation (1.1) are strictly positive and sum to unity. 


$$
\varepsilon_{i t} \equiv S_{i t}-S_{i t}^{e}
$$

equals the discrepancy between the actual and theoretical bond yields.

The Campbell-Shiller approach to testing the expectations theory of the term structure relies on a comparison of the evolutions of actual and theoretical spreads, where a time series of theoretical spreads is derived from forecasts of future short rate changes computed from a bivariate vector autoregression (VAR). The VAR includes the actual spread, $S_{i t}$, and the change in the short rate, $\Delta r_{i t}$. The approach allows formal statistical tests of the hypothesis that the actual long/short spread equals its theoretical counterpart under the expectations theory. However, the main advantage of the Campbell-Shiller methodology is that it permits an assessment of the economic significance of deviations of interest rates from levels predicted by the expectations theory. For example, the methodology allows one to compute an estimate of the standard deviation of the discrepancies $\left(\varepsilon_{i t} s\right)$.

This standard deviation enables one to form a judgement on the relative importance of the discrepancies for interest rate spread volatility.

\subsection{VAR-based specification tests of the expectations theory}

There are two standard VAR-based specification tests of the expectations theory of the term structure associated with the Campbell-Shiller approach. The first is the sample correlation between actual and theoretical spreads, $\rho \equiv \operatorname{corr}\left(S, S^{e}\right)$. The second is the ratio of standard deviations $\sigma\left(S^{e}\right) / \sigma(S)$, where $\sigma$ denotes sample standard deviation. In large samples, these statistics should be unity if the expectations theory is true. When the expectations theory fails, the distance from unity of the values of these statistics sheds light on the empirical content of the expectations theory as a model of interest rate behaviour.

In addition to these by now standard specification tests of the expectations theory, this study also reports the sample standard deviation of the discrepancy between the actual and theoretical long/short spread, $\sigma(\varepsilon)$. This measure might also provide information about the empirical content of the expectations theory.

The results of applying the Campbell-Shiller methodology to the study of long/short interest rate spreads in five countries are reported below. The short-term (one-period) rate is the threemonth rate. The long rate is a five-year government bond yield. Thus, in the context of equation (1.1), one period equals three months and $n=20$. The data are quarterly and all interest rates are end-ofquarter values. 


\section{Actual and theoretical spreads*}
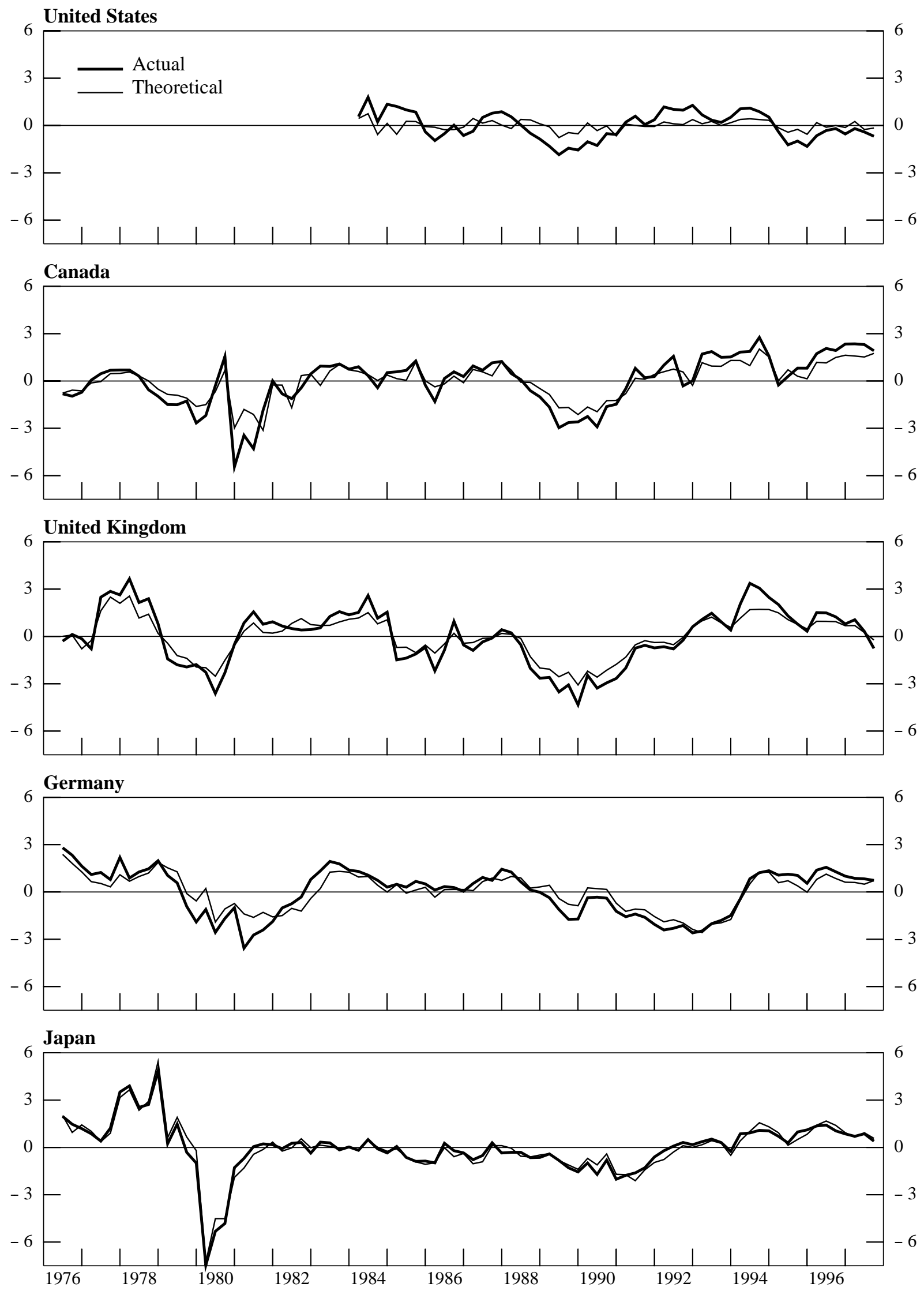

* De-meaned spreads between the five-year government bond yield and three-month money market rate. Theoretical spreads are computed from VAR-based forecasts of future changes in the three-month rate. 
Table 1

VAR-based tests of expectations theory

\begin{tabular}{|l|c|c|c|c|c|}
\hline & $\begin{array}{c}\text { United } \\
\text { States }\end{array}$ & Canada & $\begin{array}{c}\text { United } \\
\text { Kingdom }\end{array}$ & Germany & Japan \\
\cline { 2 - 6 } & 0.613 & 0.936 & 0.975 & 0.924 & 0.980 \\
$\sigma\left(S^{e}\right) / \sigma(S)$ & $(0.005)$ & $(0.086)$ & $(0.238)$ & $(0.999)$ & $(0.054)$ \\
& 0.368 & 0.686 & 0.708 & 0.765 & 0.989 \\
$\sigma(\varepsilon)$ & $(0.007)$ & $(0.041)$ & $(0.042)$ & $(<0.001)$ & $(0.234)$ \\
& 0.729 & 0.687 & 0.618 & 0.598 & 0.327 \\
\hline
\end{tabular}

Note: For all countries except the United States, the estimation period is 1976 Q2-1997 Q3. For the United States, the estimation period is 1984 Q1-1997 Q3. Numbers in parentheses are significance probabilities computed by Monte Carlo simulation. In the case of both the correlation coefficient and the standard deviation ratio, the reported significance probabilities are the fraction of 1,000 runs for which a value of the statistic less than that reported in the table was obtained.

Table 1 reports the results of the specification tests of the expectations theory discussed above. The statistic $\rho$ is the correlation coefficient between actual and theoretical spreads. Theoretical spreads are computed from VAR-based forecasts of quarterly changes in three-month rates. For each country, the VAR includes four lags of the actual spread and four lags of the change in the threemonth rate. For all countries except the United States, the estimation period is 1976 Q2--1997 Q3.4 For the United States, the estimation period is 1984 Q1--1997 Q3, so that the period of non-borrowed reserve targeting, which began in the late 1970s, is not included in the sample.

The correlation coefficient $\rho$ is close to unity for all countries except the United States. Significance probabilities, computed by Monte Carlo simulation, are reported in parentheses below the correlation coefficients. ${ }^{5}$ The significance probabilities represent the estimated probability of obtaining a value of $\rho$ less than that reported if the expectations theory of the term structure holds. Only in the case of the United States can the expectations theory be rejected, on the basis of the correlation statistic, at the $5 \%$ level of confidence.

The relatively low correlation between actual and theoretical spreads in the United States might be taken as evidence of relatively large deviations of long-term interest rates from levels predicted by the expectations theory. It is interesting to note that Hardouvelis (1994), in his study of ten-year bond yields in the G-7 countries, also reports a relatively low correlation between actual and theoretical spreads in the United States.

4 The starting date of the period studied is determined by the Japanese three-month rate, which is available only from the first quarter of 1975 (1975 Q1). Allowing for four lags in the VAR and the loss of one observation due to differencing the short rate gives a starting date for the estimation of 1976 Q2.

5 The Appendix describes in detail the assumptions underlying the Monte Carlo experiments and explains how they were conducted. 
The other standard VAR-based specification test of the expectations theory, the ratio of the standard deviation of the theoretical long/short spread to the standard deviation of the actual spread, is also reported in Table 1. In all of the countries studied except Japan the ratio of standard deviations is significantly less than unity. Significance probabilities are shown in parentheses below the standard deviation ratios, and represent the estimated probability of obtaining a value of the standard deviation ratio less than that reported if the expectations theory of the term structure holds. On the basis of this specification test, and a 5\% confidence level, the expectations theory of the term structure is rejected in every country except Japan.

It is interesting to note that the standard deviation ratio test statistic allows the rejection of the expectations theory in Japan at about the $20 \%$ confidence level, even though the ratio of standard deviations is almost unity. The fact that a value of unity of the standard deviation ratio lies in the left tail of the distribution of ratios generated by Monte Carlo simulation suggests that the estimated coefficients of the VAR, from which forecasts of short-rate changes are derived, are contaminated with substantial estimation error. Estimation error in the coefficients of the VAR would tend to cause the ratio $\sigma\left(S^{e}\right) / \sigma(S)$ to be greater than unity in small samples under the expectations theory, even though in large samples the ratio would be close to unity. ${ }^{6}$

The reported ratios of standard deviations suggest that, in every country except Japan, actual long/short spreads are substantially more volatile than the expectations theory would predict. This suggests that non-negligible $\varepsilon_{i t}$ s are an important source of bond yield volatility for most of the markets studied. Indeed, the last row of Table 1 shows, for each country, the standard deviation of the discrepancy between the actual and theoretical spread, $\sigma\left(\varepsilon_{i t}\right)$. For the countries for which the expectations theory is statistically rejected - the United States, Canada, the United Kingdom and Germany - this standard deviation runs from about 60 basis points (Germany) to over 70 basis points (the United States).

\section{Spread overreaction and comovements of term premia between countries}

Given the relative importance of the discrepancies $\left(\varepsilon_{i t} \mathrm{~s}\right)$ for the volatilities of long/short interest rate spreads documented in the preceding section, an important question that arises is how to characterise these discrepancies. For instance, should they be viewed as white noise deviations of long rates from levels predicted by the expectations theory, or is a more complicated model required? Are the discrepancies correlated across markets?

6 Previous studies (Campbell and Shiller (1991) and Bekaert, Hodrick and Marshall (1997)) have also documented important discrepancies between the small-sample distributions of regression tests of the expectations theory and the distributions implied by the relevant asymptotic theory. 
As Campbell and Shiller (1991) observe, the simplifying assumption that $\varepsilon_{i t}$ is orthogonal to $S_{i t}^{e}$, as would be the case if the $\varepsilon_{i t}$ s were white noise error terms, implies that

$$
\rho=\sigma\left(S_{i t}^{e}\right) / \sigma\left(S_{i t}\right)=\sqrt{1 /\left(1+v_{i}\right)}
$$

where $v_{i}$ is the ratio of the variance of $\varepsilon_{i t}$ to the variance of $S_{i t}^{e}$. As shown in Table 1 , for the majority of countries studied the correlation coefficient substantially exceeds the standard deviation ratio. This suggests that the assumption that $\varepsilon_{i t}$ is orthogonal to $S_{i t}^{e}$ is not satisfied by the data.

\subsection{Spread overreaction hypothesis}

An alternative hypothesis concerning the $\varepsilon_{i t}$ s is that they are generated by the spread overreaction hypothesis that Campbell and Shiller (1991) conclude roughly fits the US data. The spread overreaction hypothesis can be given formal content by assuming that the actual long/short spread is a linear transformation of the theoretical spread

$$
S_{i t}=\beta_{0 i}+\beta_{1 i} S_{i t}^{e},
$$

where $\beta_{0 i}$ and $\beta_{1 i}$ are parameters of the transformation. The expectations theory of the term structure is nested in equation (2.2) and obtains when $\beta_{0 i}=0$ and $\beta_{1 i}=1$. In contrast, the spread overreaction hypothesis is given by the class of models where $\beta_{1 i}>1$.

Under the spread overreaction hypothesis $\left(\beta_{1 i}>1\right)$, there is a systematic overreaction of the actual long/short spread to changes in the theoretical spread, $S_{i t}^{e}$. Recalling that $S_{i t}^{e}=R_{i t}^{e}-r_{i t}$, it is clear that when $\beta_{1 i}>1$ the long/short spread overreacts to changes in expected future short rates embodied in $R_{i t}^{e}$; the long rate would change by less if the expectations theory held. In this case, it is easily shown that the discrepancy between the actual and theoretical spread in country $i, \varepsilon_{i t}$, is positively correlated with the theoretical spread in country $i$.

It is of interest to note the implications of equation (2.2) for the values of the statistics reported in Table 1. Under equation (2.2), the correlation between the actual and theoretical spreads will be unity provided only that $\beta_{1}>0$. Thus, the correlation coefficient has limited statistical power to detect the departures from the expectations theory modelled by equation (2.2). In contrast, under (2.2), the ratio $\sigma\left(S_{i t}^{e}\right) / \sigma\left(S_{i t}\right)$ equals $1 / \beta_{1}$, so that it is possible on the basis of the standard deviation ratio statistic to detect failures of the expectations theory of the type modelled by equation (2.2).

As reported in Table 1, the ratio of standard deviations is substantially less than unity for every country except Japan. This is consistent with the spread overreaction hypothesis $\left(\beta_{1}>1\right)$ holding in the majority of countries studied. A direct test of the spread overreaction hypothesis can be conducted by estimating the parameters of equation (2.2). Ordinary least squares (OLS) estimates of equation (2.2) are reported in Table 2 , and for every country except Japan $\hat{\beta}_{1}>1$. The country that 
shows the greatest degree of spread overreaction is the United States, the country for which the hypothesis was initially offered as an explanation for the apparent failure of the expectations theory of the term structure. Nevertheless, with the exception of Japan, the other countries studied also display a substantial degree of spread overreaction, especially when one recalls that the variable $S_{i t}^{e}$ is measured with error, so that OLS estimates of the parameter $\beta_{1}$ are biased towards zero. ${ }^{7}$ Significance probabilities, reported in parentheses in Table 2, indicate that the evidence in favour of the spread overreaction hypothesis in the United States, Canada, the United Kingdom and Germany is statistically significant at a high level of confidence. This implies that, in these countries, the discrepancy between the actual and theoretical spread, $\varepsilon_{i t}$, is positively correlated with the theoretical spread.

Table 2

OLS estimates of equation (2.2)

\begin{tabular}{|l|c|c|c|c|c|}
\hline & $\begin{array}{c}\text { United } \\
\text { States }\end{array}$ & Canada & $\begin{array}{c}\text { United } \\
\text { Kingdom }\end{array}$ & Germany & Japan \\
\cline { 2 - 6 }$\beta_{\mathbf{0}}$ & 1.631 & 0.007 & 0.178 & 0.944 & 0.588 \\
$\beta_{\mathbf{1}}$ & $\begin{array}{c}1.667 \\
(0.014)\end{array}$ & $(0.018)$ & $\begin{array}{c}1.376 \\
(0.029)\end{array}$ & $\begin{array}{c}1.206 \\
(<0.001)\end{array}$ & $\begin{array}{c}0.992 \\
(0.231)\end{array}$ \\
\hline
\end{tabular}

Note: For all countries except the United States, the estimation period is 1976 Q2-1997 Q3. For the United States, the estimation period is 1984 Q1-1997 Q3. Numbers in parentheses are significance probabilities computed by Monte Carlo simulation. The reported significance probabilities are the fraction of 1,000 runs for which an estimate of $\beta_{1}$ greater than that reported in the table was obtained.

\subsection{Comovements of term premia between countries}

The overreaction of actual long/short interest rate spreads to their theoretical counterparts has implications for the comovements of bond yields between countries. In particular, under equation (2.2) it follows that

$$
\operatorname{Cov}\left(\varepsilon_{i t}, \varepsilon_{j t}\right)=\left(\beta_{1 i}-1\right) *\left(\beta_{1 j}-1\right) * \operatorname{Cov}\left(S_{i t}^{e}, S_{j t}^{e}\right)
$$

Thus, if the spread overreaction hypothesis holds for both countries $i$ and $j$, that is, $\beta_{1 i}>1$ and $\beta_{1 j}>1$, then the covariance between the discrepancies $\varepsilon_{i t}$ and $\varepsilon_{j t}$, which are de-meaned term premia, has the same sign as the covariance between the theoretical spreads $S_{i t}^{e}$ and $S_{j t}^{e}$.

Recall that theoretical spreads are, by equation (1.3), determined by expected changes in short rates. Therefore, the intercountry covariances of theoretical spreads depend upon cross-country

7 Recall that $S_{i t}^{e}$ is formed from VAR-based forecasts of changes in the three-month rate of interest. To the extent that the estimated coefficients of the VAR are subject to sampling error, this error will be transmitted to the variable $S_{i t}^{e}$. 
covariances of expected changes in short rates. Table 3 reports cross-country correlations of theoretical spreads. All of the correlations are positive, which reflects the tendency of VAR-based forecasts of short rate changes to be positively correlated across countries.

Table 3

Cross-country correlations of theoretical spreads

\begin{tabular}{|l|c|c|c|c|c|}
\hline & US & Canada & UK & Germany & Japan \\
\cline { 2 - 6 } United States & 1.00 & & & & \\
Canada & 0.43 & 1.00 & & & \\
United Kingdom & 0.41 & 0.81 & 1.00 & 1.00 & \\
Germany & 0.02 & 0.16 & 0.16 & 0.40 & 1.00 \\
Japan & 0.19 & 0.65 & 0.72 & \\
\hline
\end{tabular}

Note: The sample period is 1984 Q1 - 1997 Q3.

Table 4

Cross-country correlations of discrepancies $(\varepsilon)$

\begin{tabular}{|l|c|c|c|c|c|}
\hline & US & Canada & UK & Germany & Japan \\
\cline { 2 - 5 } United States & 1.00 & & & & \\
Canada & 0.41 & 1.00 & & & \\
United Kingdom & 0.39 & 0.50 & 1.00 & 1.00 & \\
Germany & 0.19 & 0.44 & 0.50 & 0.05 & 1.00 \\
Japan & 0.24 & 0.30 & -0.02 & & \\
\hline
\end{tabular}

Note: The estimation period is 1984 Q1 - 1997 Q3.

Positive intercountry correlation of theoretical spreads has implications for the intercountry correlation of term premia. In particular, for groups of countries for which the spread overreaction hypothesis holds, term premia will be positively correlated between countries. Table 4 reports cross-country correlations of the discrepancies between actual and theoretical spreads. The discrepancies are indeed positively correlated within the group of countries for which the spread overreaction hypothesis holds - the United States, Canada, the United Kingdom and Germany. This is further evidence of the "excess comovement of bond yields" documented in Sutton (1997). 


\section{Conclusions}

This paper applies the Campbell-Shiller (1987) methodology to a study of the joint behaviour of a three-month and a five-year government yield in the United States, Canada, the United Kingdom, Germany and Japan. The period studied is for most countries the mid-1970s to the third quarter of 1997. The empirical results allow the rejection of the expectations theory of the term structure at high levels of statistical significance in every country except Japan. Furthermore, in every country where the expectations theory fails, the failure of the theory is consistent with the spread overreaction hypothesis of Froot (1989) and Campbell and Shiller (1991). This implies that the departures of long rates from levels predicted by the expectations theory in many major markets cannot be attributed to white noise error terms.

Spread overreaction has implications for the comovements of bond yields between countries. Because expected changes in short-term interest rates tend to be positively correlated between countries, spread overreaction implies that the discrepancies between bond yields and their theoretical counterparts under the expectations theory are positively correlated across markets. Thus, spread overreaction can be considered to be part of the reason for the excess comovement of bond yields documented in previous research. 


\section{Appendix: Monte Carlo experiments}

This appendix describes in detail the assumptions underlying the Monte Carlo simulations and explains how they were conducted.

The short-term (three-month) interest rate in country $i, r_{i t}$, is assumed to follow the firstorder autoregressive process

$$
r_{i t}=\alpha_{0 i}+\alpha_{1 i} r_{i t-1}+\eta_{i t}
$$

where $\eta_{i t}$ is an independent (over time), identically distributed normal random variable with zero mean.

Table A.1

Estimates of equation (A.1)

\begin{tabular}{|l|c|c|c|c|c|}
\hline & $\begin{array}{c}\text { United } \\
\text { States }\end{array}$ & Canada & $\begin{array}{c}\text { United } \\
\text { Kingdom }\end{array}$ & Germany & Japan \\
\cline { 2 - 6 } OLS estimates: & 0.77 & 0.74 & 0.84 & 0.25 & 0.80 \\
$\alpha_{\mathbf{0}}$ & 0.89 & 0.92 & 0.92 & 0.96 & 0.84 \\
$\alpha_{\mathbf{1}}$ & & & & & \\
Bias-adjusted & 0.46 & 0.34 & 0.44 & 0.00 & 0.61 \\
estimates: & 0.94 & 0.96 & 0.96 & 1.00 & 0.88 \\
$\alpha_{\mathbf{0}}$ & & & & \\
$\alpha_{\mathbf{1}}$ & & & & & \\
\hline
\end{tabular}

Note: The estimation period is 1975 Q2-1997 Q3. "Bias-adjusted" estimates are derived from the OLS estimates and the bias adjustment formulas given in Bekaert, Hodrick and Marshall (1997). The bias adjustment formulas assume that the unconditional mean of the short rate process exists. In the case of Germany, the bias-adjusted estimated of $\alpha_{1}$ is 1.0 , implying a non-stationary short rate process. For Germany, the short rate is assumed to follow a random walk without drift.

Table A.1 reports OLS estimates of the parameters of equation (A.1). The OLS estimates of $\alpha_{0}$ and $\alpha_{1}$ shown in Table A.1 are subject to small-sample bias. In particular, the OLS estimate of $\alpha_{1}$ is subject to downward bias. In a recent paper, Bekaert, Hodrick and Marshall (1997) emphasise the importance of correcting for small-sample bias when evaluating the statistical significance of regression tests of the expectations theory by Monte Carlo methods. Table A.1 also reports "biasadjusted" estimates of $\alpha_{0}$ and $\alpha_{1}$ which are derived from the OLS estimates and the bias adjustment formulas given in Bekaert, Hodrick and Marshall (1997). In the Monte Carlo simulations, the biasadjusted estimates of $\alpha_{0}$ and $\alpha_{1}$ are, for each country, taken as parameters in equation (A.1).

One thousand series of artificial short rates were generated for each country according to (A.1), where the standard deviation of $\eta_{i t}$ is, for each country, set equal to the sample standard 
deviation over the period 1975 Q2-1997 Q3. (The value of $r_{i t}$ in 1975 Q1 is taken as an initial condition.) Corresponding to each series of artificial short rates, a series of artificial five-year bond yields was constructed according to equation (1.1), where expectations of future short rates were assumed to be consistent with (A.1). A bivariate VAR (in the long/short spread and the change in the short rate) was fitted to each pair of generated interest rates. The estimated VAR was then used to generate expected short rate changes and a theoretical long/short spread consistent with these expectations. The significance probabilities reported in Tables 1 and 2 were computed from these series. 


\section{References}

Bekaert, Geert, Robert J. Hodrick and David A. Marshall (1997): "On Biases in Tests of the Expectations Hypothesis of the Term Structure of Interest Rates". Journal of Financial Economics, Vol. 44, pp. 309-48.

Campbell, John Y. and Robert J. Shiller (1984): “A Simple Account of the Behavior of Long-Term Interest Rates". American Economic Review, Vol. 74, pp. 44-8.

Campbell, John Y. and Robert J. Shiller (1987): "Cointegration and Tests of Present Value Models". Journal of Political Economy, Vol. 95, pp. 1062-88.

Campbell, John Y. and Robert J. Shiller (1991): "Yield Spreads and Interest Rate Movements: A Bird's Eye View". Review of Economic Studies, Vol. 58, pp. 495-514.

Fama, Eugene F. (1984): “The Information in the Term Structure”. Journal of Financial Economics, Vol. 13, pp. 509-28.

Fama, Eugene F. and Robert R. Bliss (1987): “The Information in Long-Maturity Forward Rates". American Economic Review, Vol. 77, pp. 680-92.

Froot, Kenneth A. (1989): "New Hope for the Expectations Hypothesis of the Term Structure of Interest Rates". Journal of Finance, Vol. 44, pp. 283-305.

Hardouvelis, Gikas A (1994): "The Term Structure Spread and Future Changes in Long and Short Rates in the G7 Countries: Is There a Puzzle?" Journal of Monetary Economics, Vol. 33, pp. $255-83$.

Shiller, Robert J. (1979): "The Volatility of Long-Term Interest Rates and Expectations Models of the Term Structure”. Journal of Political Economy, Vol. 87, pp. 1190-219.

Shiller, Robert J., John Y. Campbell and Kermit L. Schoenholtz (1983): "Forward Rates and Future Policy: Interpreting the Term Structure of Interest Rates". Brookings Papers on Economic Activity, Vol. 1, pp. 173-217.

Sutton, Gregory D. (1997): “Is There Excess Comovement of Bond Yields Between Countries?" BIS Working Papers, No. 44. 



\section{Recent BIS Working Papers}

No.

38

October 1996

39

January 1997

40

March 1997

41

May 1997

42

June 1997

43

July 1997

44

July 1997

45

August 1997

46

September 1997

47

September 1997

48

September 1997

49

September 1997

50

November 1997

51

November 1997

52

January 1998

53

March 1998

54

June 1998
Title

International agreements in the area of banking and finance: accomplishments and outstanding issues

Banking system failures in developing and transition countries: diagnosis and prediction

Monetary policy operating procedures in industrial countries

The euro and European financial markets

Measuring monetary policy shocks in France, Germany and Italy: the role of the exchange rate

Exchange rate regimes and the expectations hypothesis of the term structure

Is there excess comovement of bond yields between countries?

A multi-country comparison of the linkages between inflation and exchange rate competitiveness

Global asset allocation in fixed income markets

Financial asset prices and monetary policy: theory and evidence

Some multi-country evidence on the effects of real exchange rates on output

Why does the yield curve predict economic activity?

Dissecting the evidence for Germany and the United States

The euro and the dollar

Forecast errors and financial developments

Inflation and disinflation in Iceland

Exchange rate regimes and inflation and output in SubSaharan countries

The coming transformation of continental European banking?
Author

William R. White

Patrick Honohan

Claudio E. V. Borio

Robert N. McCauley and William R. White

Frank Smets

Stefan Gerlach and Frank Smets

Gregory D. Sutton

Steven B. Kamin

Srichander

Ramaswamy

Frank Smets

Steven B. Kamin and Marc Klau

Frank Smets and Kostas Tsatsaronis

Robert N. McCauley

Palle S. Andersen

Palle S. Andersen and Már Guðmundsson

Marc Klau

William R. White 